\title{
Fallece connotado actor chileno, Franklin Caicedo (1928-2013)
}

\section{Pedro Bravo-Elizondo}

El Sindicato de Actores de Chile (SIDARTE) informó en su página web del fallecimiento del actor Franklin Caicedo, acaecido en Santiago el 22 de marzo de 2013. Nació en Iquique, Chile, en 1928. Desde joven se interesó por el teatro y en Santiago ingresó a la Escuela del Teatro Experimental de la Universidad de Chile. Al finalizar sus estudios realizó giras con el grupo por América Latina. En 1960 participó bajo la dirección de Domingo Tessier en el primer teleteatro "Relato de mineros" sobre un cuento de Oscar Castro. En 1962 la "Compañía de Los Cuatro"-Humberto y Héctor Duvauchelle, Orietta Escámez, dirigidos por Caicedo-presentó Boing-Boing de Marc Camoletti, que fue considerada como una obra bien interpretada y dirigida.

Caicedo, continuando una gran tradición iquiqueña, dictó clases de teatro a grupos obreros en Santiago, guiado tal vez por la experiencia de los teatros obreros del puerto, que comenzó con el Conjunto Arte y Revolución creado por Luis E. Recabarren en 1912 y el Ateneo Obrero, anarquista, con su Conjunto Domingo Gómez Rojas en 1932. Franklin Caicedo dirigió Fulgory muerte de Joaquín Murieta de Pablo Neruda, con quien mantuvo una estrecha relación, según los periódicos. Pedro Orthous la estrenó antes en 1967, en el Teatro Antonio Varas del ITUCH (Instituto de Teatro de la Universidad de Chile). Caicedo fue también actor de cine, interviniendo en lo que se considera el Nuevo Cine Chileno en 1957 en la cinta Tres miradas a la calle, dirigida por Naúm Kramarenco. En 1969, en una de las giras llegó a Buenos Aires, centro de la actividad teatral sudamericana, lugar donde decidió quedarse y continuar sus estudios.

Fue en Buenos Aires donde Franklin Caicedo y otros chilenos del período, como Lautaro Murúa (iquiqueño) y Patricio Contreras, destacaron en el plano artístico. Caicedo participó en teatro, cine y televisión. En cine, intervino en La Patagonia rebelde, dirigida por Héctor Olivera. Caicedo re- 
presentó el rol del "chileno" Farina y uno de los extras fue nada menos que el futuro presidente de Argentina, Néstor Kirchner (2003-2007). Otras películas fueron: La isla, dirigida por Fernando Doria (1979); Tacos altos, dirigida por Sergio Renán (1985); Yo, la peor de todas, dirigida por María Luisa Bemberg (1990). Recibió innumerables premios y realizó giras por Egipto, Estados Unidos, Suecia, Venezuela y Cuba. En el 2007 cumplió el ciclo chileno al interpretar a Pablo Neruda, en la versión argentina de El cartero de Neruda de Antonio Skármeta. Caicedo falleció en Santiago en el hospital Sótero del Río la mañana del viernes 22 de marzo del 2013.

Wichita State University 